\title{
Effect of hydroalcoholic extract of Ferula assa-foetida $L$. resin on rheumatoid arthritis symptoms in the collagen- induced animal model
}

\author{
Maryam Mohammadi ${ }^{1}$ (D), Gholamreza Anani Sarab ${ }^{2}(D)$, \\ Hosein Ghaini Mohammad ${ }^{3}$ (D) Roya Yaraee ${ }^{4}$
}

\footnotetext{
${ }^{1}$ Master student of Immunology, Faculty of Medicine,Shahed university,Tehran,Iran

${ }^{2}$ Department of Immunology, School of Medicine,Birjand University of Medical Sciences,Birjand,Iran.

${ }^{3}$ Department of Pathology, Faculty of Medicine, Shahed University, Tehran, Iran.

${ }^{4}$ Corresponding auuthor; Department of Immunology, Faculty of Medicine, Shahed University, Tehran, Iran. Email:ryaraee@yahoo.com
}

Citation Mohammadi M, Anani Sarab Gh, Ghaini Mohammad H,Yaraee R. [Effect of hydroalcoholic extract
of Ferula assa-foetida L. resin on rheumatoid arthritis symptoms in collagen-induced animal model]. J
Birjand Univ Med Sci. 2020; 27(1): 33-43. [Persian]

\begin{abstract}
Background and Aim: Rheumatoid arthritis (RA) is a chronic, autoimmune inflammatory disease that affects synovial tissue. According to potential side effects of current treatments, interest in using complementary and alternative medicine(CAM) has reappeared.The purpose of this study was to evaluate the effect of extract of Ferula assa-foetida L. resin on the severity of rheumatoid arthritis symptoms in the collagen induced animal model.

Materials and Methods: In this experimental study, 30 female Wistar rats were randomly divided into 6 groups: healthy control, CIA, Dexamethasone receiving group to amount $1 \mathrm{mg} / \mathrm{kg}$, receiving group to $100 \mathrm{mg} / \mathrm{kg}$ concentration of extract of asafoetida resin, receiving group to $300 \mathrm{mg} / \mathrm{kg}$ concentration of extract of asafoetida resin and receiving group to $100 \mathrm{mg} / \mathrm{kg}$ extract and dexamethasone (mixed group). Rheumatoid arthritis was induced by the administration of collagen type 2 and adjuvant. The clinical evaluation started and the severity of the symptoms of rheumatoid arthritis, by examination and standard scoring was performed.

Results: From the thirteenth day, Symptoms of the disease appeared and from the fourteenth day, there was a significant difference between the control and CIA groups in the clinical symptom score of arthritis. Among intervention groups, receiving group to 100 $\mathrm{mg} / \mathrm{kg}$ concentration of extract earlier and more cause to decreased severity of symptoms. So on the 28th day, disease severity in the control group was 13.4 and in the treatment group with a concentration of $100 \mathrm{mg} / \mathrm{kg}$ extracts of Ferula assa-foetida L. resin was 9.6 .
\end{abstract}

Conclusion: Hydroalcoholic extract of asafoetida resin, its could reduce the severity of symptoms of ankle RA and in the dose of 100 $\mathrm{mg} / \mathrm{kg}$ cause to mitigate the symptoms of apparent swelling and inflammation.

Key Words: Arthritis Animal Model; Ferula assa-Foetida L; Rheumatoid Arthritis 


\section{تأثير عصاره هيدروالكلى صمغ آنغوزه (Ferula assa-foetida L.) بر علائم آرتريت روماتوئيد در مدل حيوانى القاشده توسط كلازٔن}

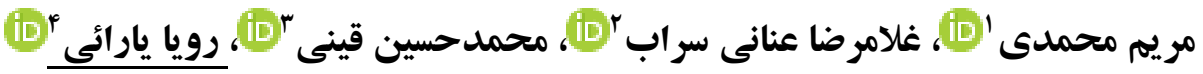

\section{جـ}

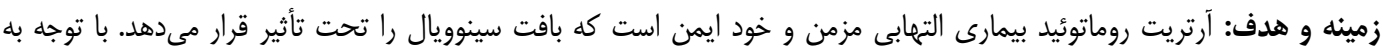

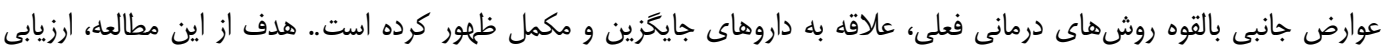

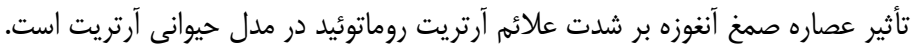

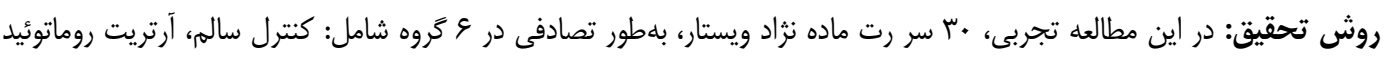

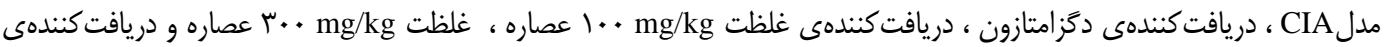

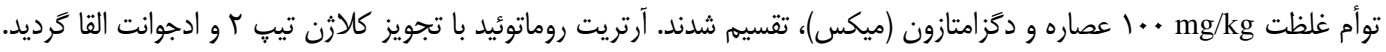

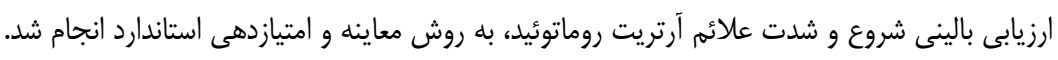

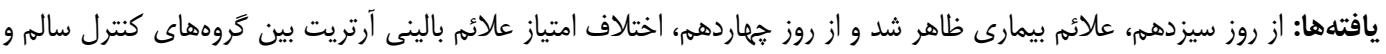

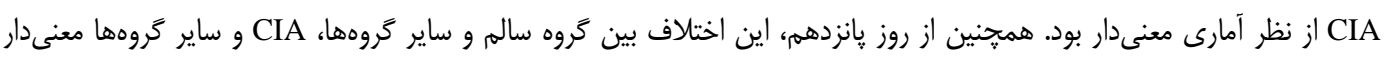

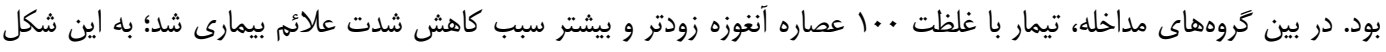

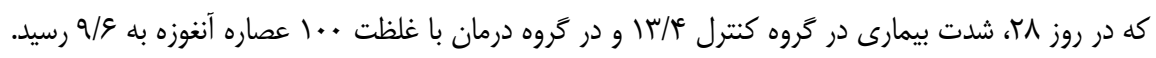

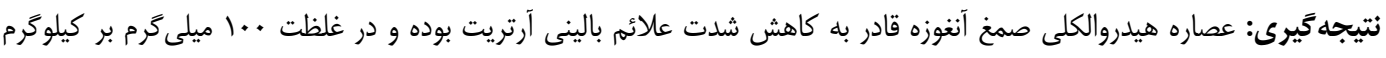

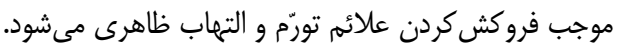
وازههاى كليدى: مدل حيوانى آرتريت؛ صمغ آنغوزه؛ آرتريت روماتوئيد مجله علمى دانشكاه علوم يزشكى بيرجند. و وس 1؛ دريافت: 
بهدست مى آيد (ه، V). خاستخاه آنغوزه، استِهاى ايران مقله (شامل: استانهاى فارس، كرمان، خراسان، يزد، سمنان،

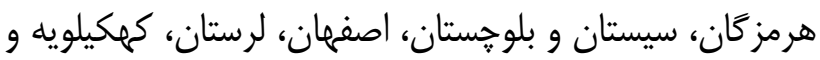

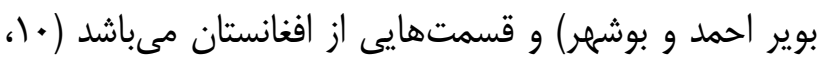

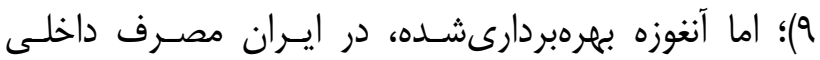

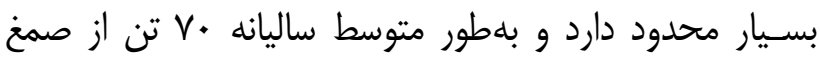
اين كياه بلهورت خام به كشورهاى مختلف صادر مى شیود

Asafoetida براى درمان بيمارىهاى مختلف به كار رود و هميجنين در

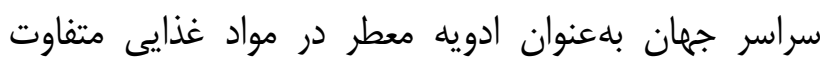

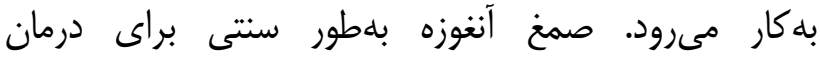
بيمارىهاى مختلف مانند: آسه، صرع، درد معار معده، نفخ، انغلاه هاى روده، هضم ضعيف و آنفولانزا استفاده مىشده است داست

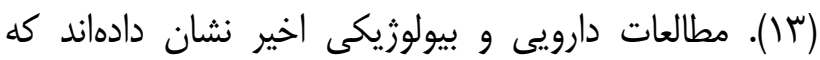
Asafoetida

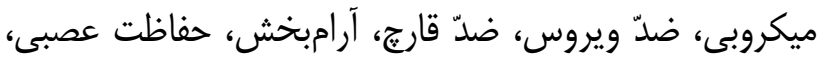

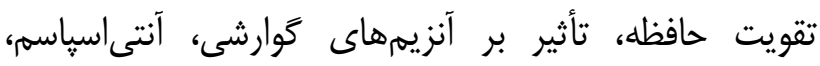

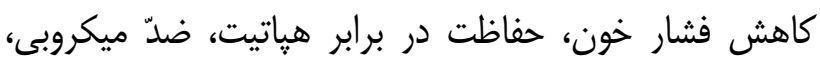

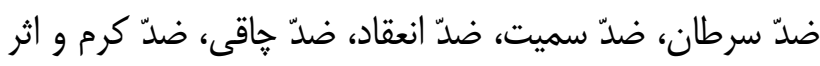

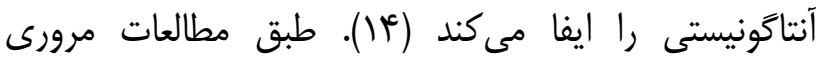

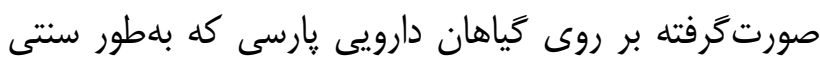

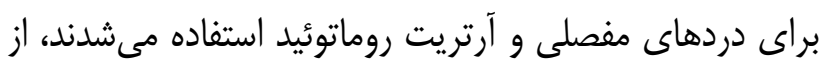
، Ferula assa- foetida L

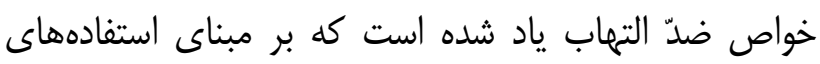

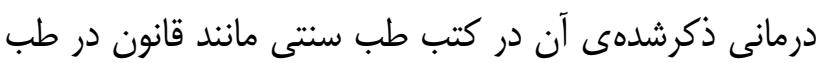

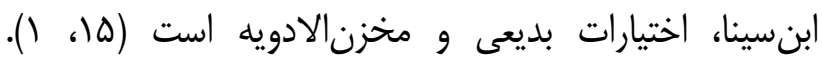
مطالعات تجربى نشان مىدهند كه تركيبات تشكيلدهنداندي

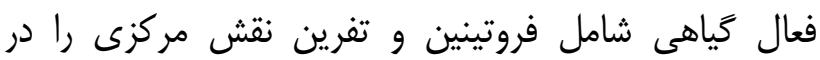

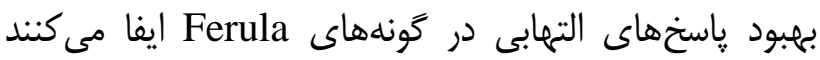

با توجه به خواص متعددى كه براى اين كياه دارويى ذكر

\footnotetext{
${ }^{1}$ Nonsteroidal anti-inflammatory drug

${ }^{2}$ Disease-modifying antirheumatic drug
}

آرتريت روماتوئيد، بيمارى التهابى مزمن و خود ايمن است كه بافت سينوويال را در مفاصل متعدد تحت تأثير قرار إنيار

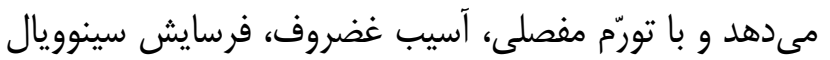

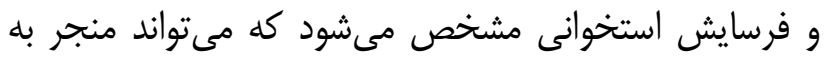

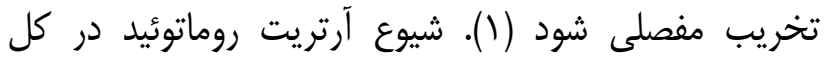

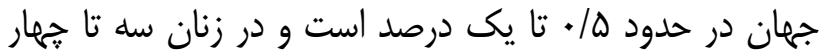
برابر نسبت به مردان شايعتر است (T). ييشرفتهايى در تعيين علت و واتورنز آرتريت روماتوئيد

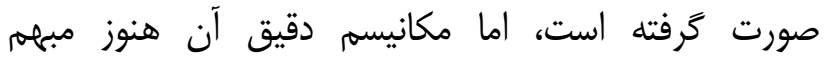
باقىمانده است. تصور مىشود سايتوكينهاى بيش التهابت التهابى كه توسط منوسيتها، ماكروفازها و فيبروبلاستهاى سينائ سينوويال توليد مىشوند، نقش مهمى در باتوزنز و ييشرفت اين بيمارى

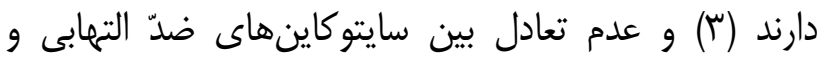
ييشالتهابى، درجه و وسعت التهاب متعاقب آسيب سلولى راني تعيين مى كند (كا، ه). روشهاى درمانى فعلى آرتريت روماتوئيد بر پإيهى محصولات تسكيندهندهى علائم بيمارى (داروهاى ضدي

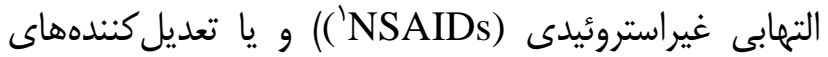
روند بيمارى (داروهاى ضدّ روماتيسمى تعديل كنندهى بيمارى

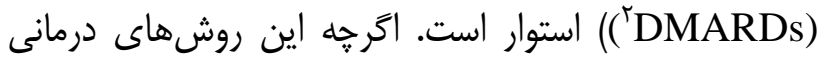
مؤثر هستند، اما بهعلت داشتن عوارض جانبى شامل:

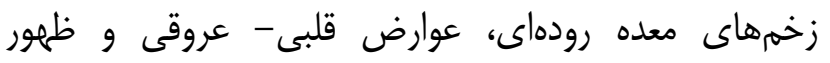
عفونتهاى فرصتطلب بهعلت سركوب سيسته ايمنى،

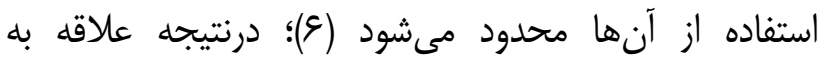

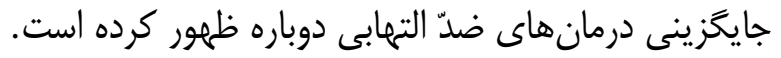

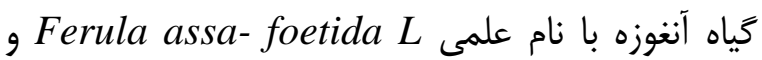
و Devil's dung Asafetida نامهاى انخليسى Food of the Gods شيرهاى است كه از تيغزدن ريشه و يا بإيين ساقه كياه 


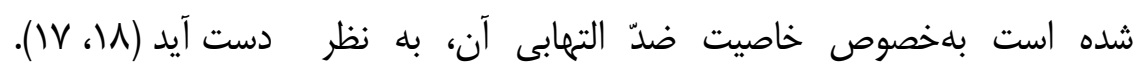

\section{القاى آرتريت روماتوئيد:}

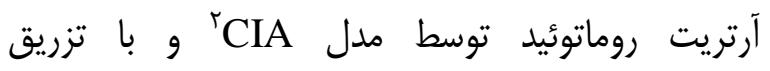

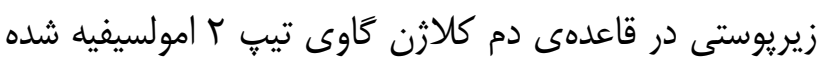

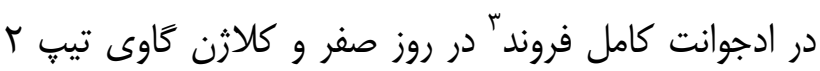

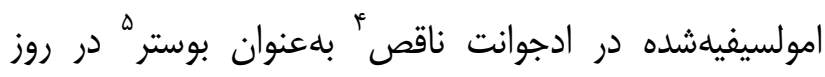

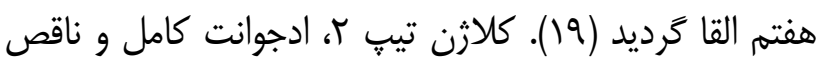

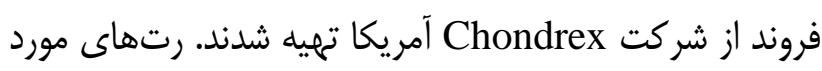

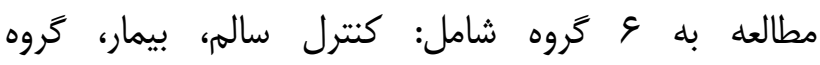

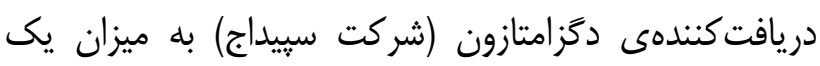

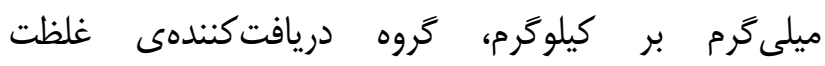

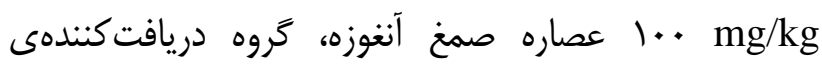

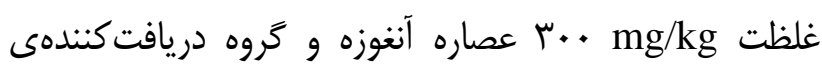
توأم غلظت ..1 عصاره و دكزامتازون (كروه ميكس) تقسيه

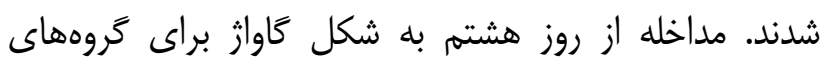

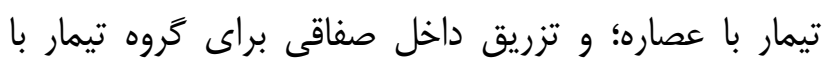

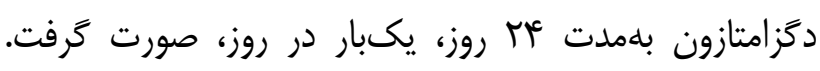

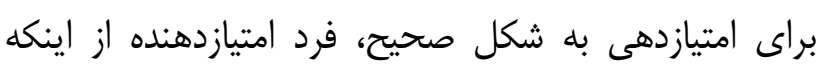
حيوان متعلق به جه گروهى است مطلع نبود.

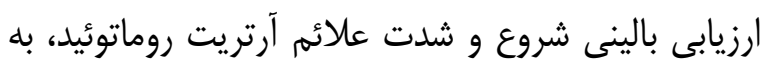

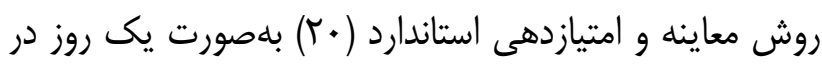

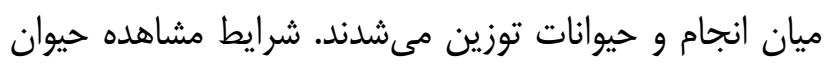

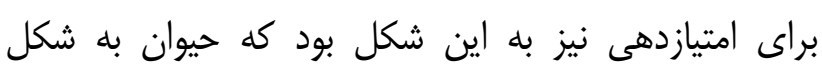

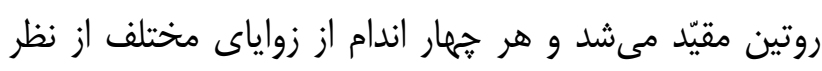
قرمزى و تورّم امتياز دهى مى مَّرديد.

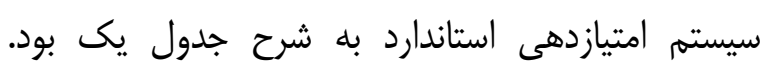

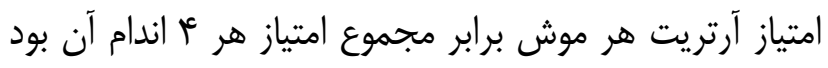
كه مىتوانست از صفر تا حداكثر عا متغير باشد.

\footnotetext{
${ }^{2}$ Collagen-induced arthritis

3 complete Freund's adjuvant

${ }_{5}^{4}$ Incomplete Freund adjuvant

5 Booster
}

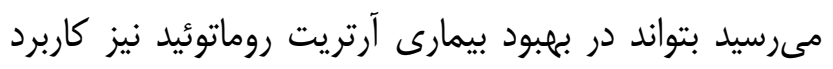

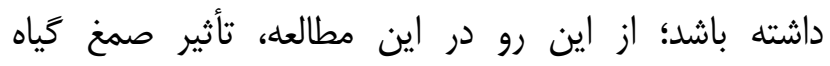

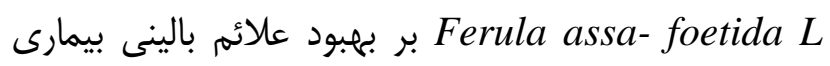

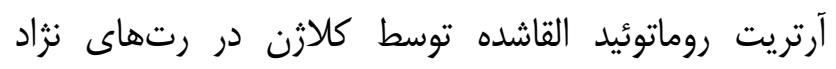
ويستار بررسى ترديد.

\section{روش تحقيق} حيوانات: - (2)

در اين مطالعه تجربى، •r سر رت ماده نزاد ويستار با

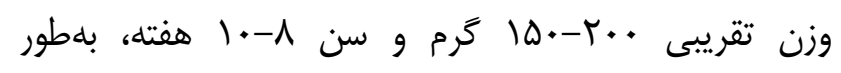

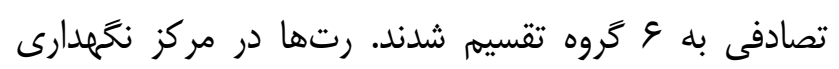

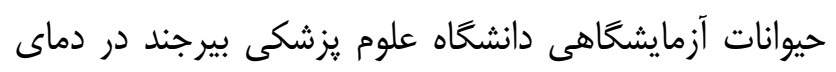

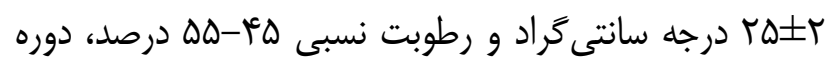

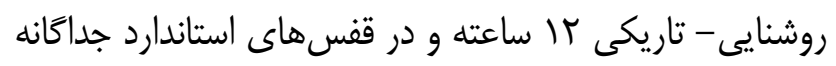

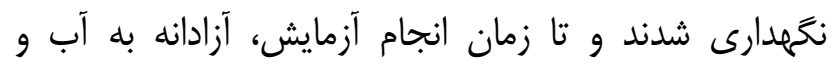

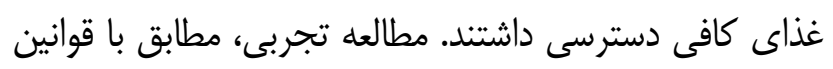

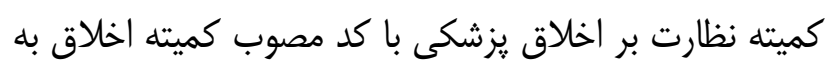
شماره IR.Shahed.REC.1396.104 انجام شد.

\section{تهيه عصاره هيدرو الكلى صمغ آنغوزه:}

صمغ آنغوزه از منطقه بومى واقع در شهرستان آنتان طبس

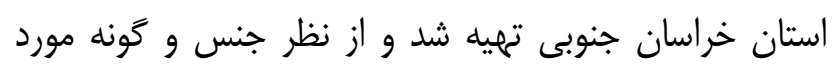

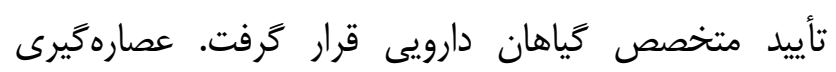

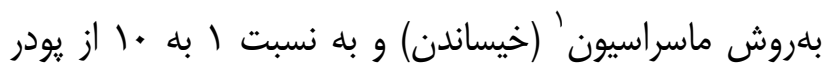

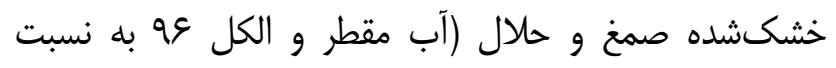

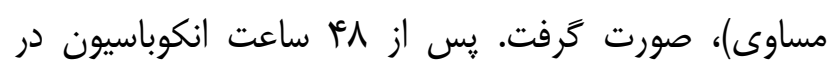

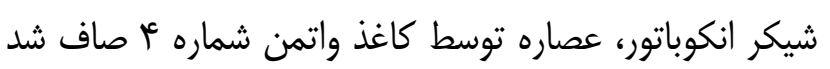

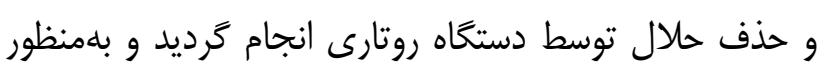

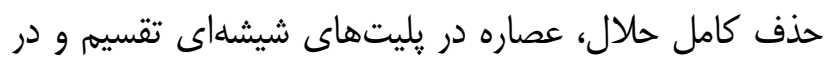

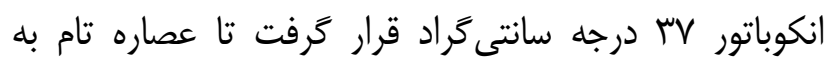


جدول ا - سيستم استاندارد رتبهبندى شدت علائم آرتريت روماتوئيد در مدل حيوانى در رت

\begin{tabular}{|c|c|}
\hline درجه التهاب & 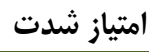 \\
\hline هيج نشانهاى از قرمزى و تورّم وجود ندارد. & • \\
\hline قرمزى و تورّم خفيف كه به مفصل مج پا يا تارسال محدود مىشود. & 1 \\
\hline قرمزى و تورّم خفيف كه از مفصل مج به ميانهى پا گسترشيافته است. & r \\
\hline قرمزى و تورّم متوسط كه از مج يا به كف پا (متاتارسال) گسترشيافته است. & r \\
\hline قرمزى و تورّم شديد كه مج يا، پا و انغشتتان را در بركرفته است. & c \\
\hline
\end{tabular}

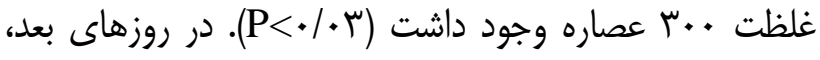

ترتيب نزولى از امتياز بالا به كم بلهترتيب به شرح زير بوداء دانس

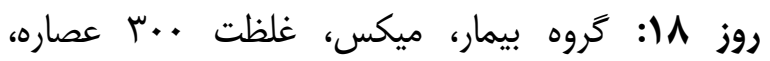

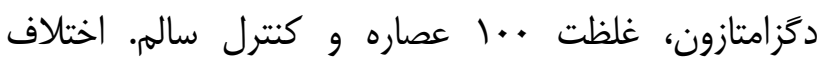

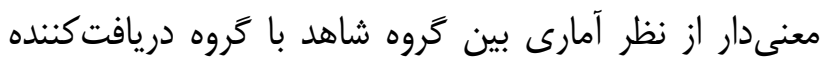

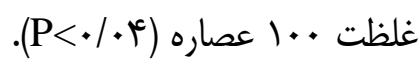

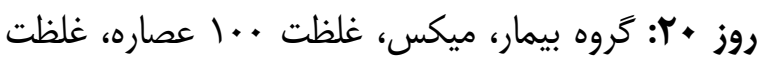

$$
\begin{aligned}
& \text {. . . عصاره، دخزامتازون، كنترل سالم. } \\
& \text { روز זr: همانند روز •r. }
\end{aligned}
$$

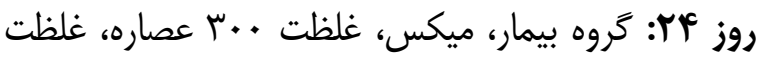

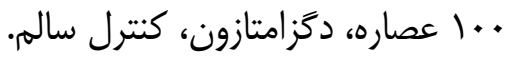

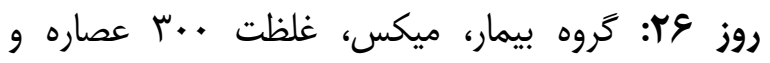
دَزامتازون، غلظت . +.

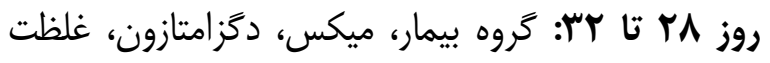

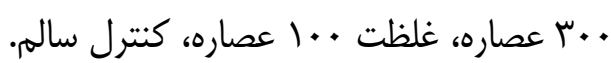

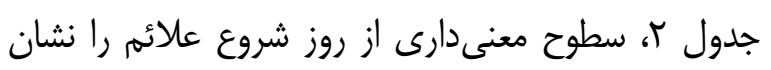
مى دهد.

\section{تجزيه و تحليل دادهها:}

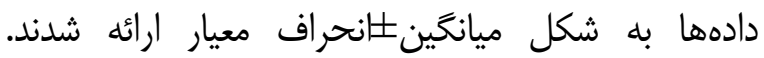

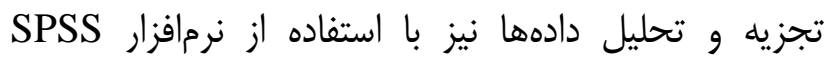

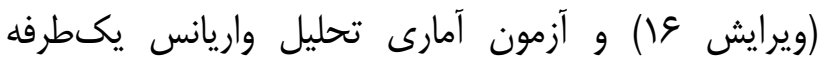
و و پسآزمون با استفاده از آزمون (One Way ANOVA) Tukey در سطح معنى دارى ه•/• انجام شد.

\section{يافتهها}

\section{علائم بيمارى:}

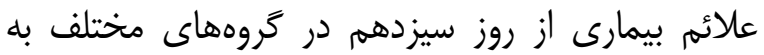
شدتهاى مختلف ظاهر شد و گروه كنترل سالم تا يايان

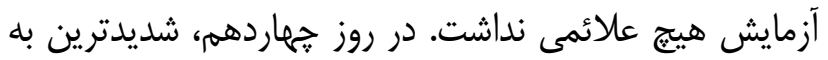

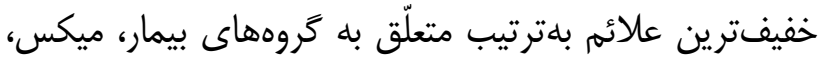

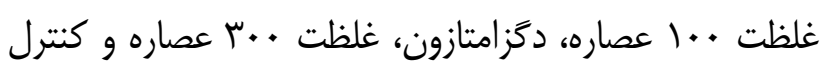

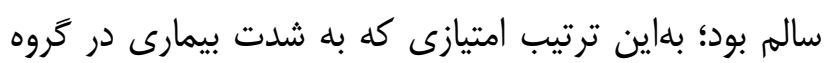

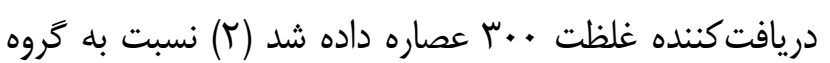

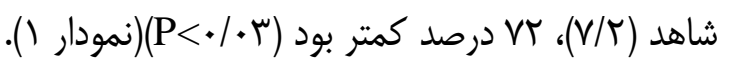
در روز شانزدهم نيز ترتيب گروهها به شكل روز جهاردها بهم

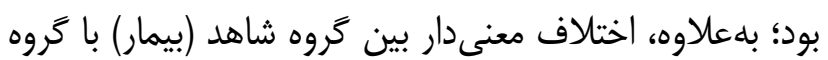


امتياز علائم طى روزهاى مطالعه
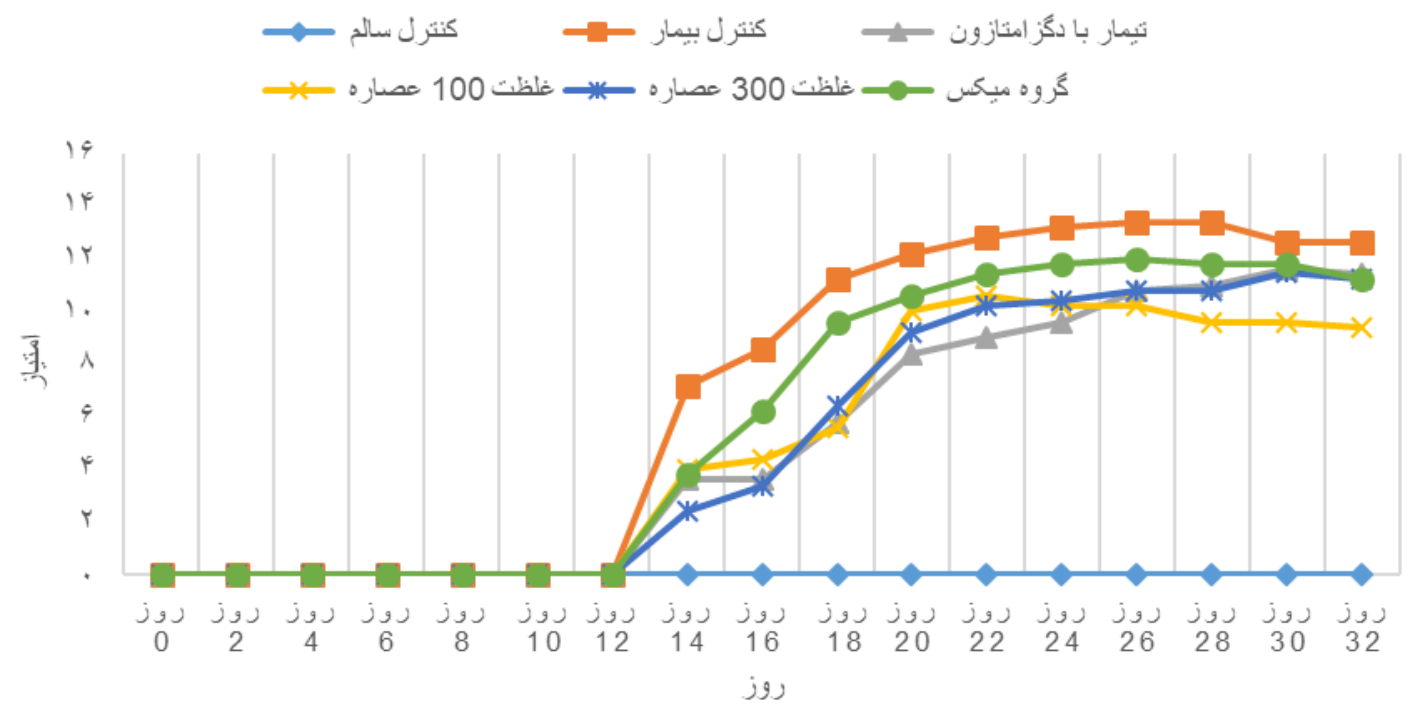

نمودار ا - مقايسه شدت بروز علائم آرتريت روماتوئيد طى روزهاى مطالعه در كَروههاى مورد مطالعه

جدول r- نتيجه تست آمارى مقايسه تَروهها با تَروه كنترل سالم در روزهاى مختلف مداخله

\begin{tabular}{|c|c|c|c|c|c|c|c|c|c|c|}
\hline $\begin{array}{l}: 3 \\
: j \\
13 \\
12 \\
2 \\
5\end{array}$ & روز If & روز \&1 & روز 11 & روز • r & روز זץ & روز Fr & روز צr & روز & روز • & روز זس \\
\hline گروه بيمار & سו•/. & $\cdot 1 \cdot+r^{c}$ & $\cdot 1 \cdot+1$ & $\cdot 1 \cdot \cdots+1$ & $\cdot 1 \cdot \cdots 1$ & $\cdot 1+\cdots 1$ & $\cdot 1 \cdot \cdots 1$ & $.1+\cdots 1$ & $.1+\cdots 1$ & $\cdot 1+\cdots 1$ \\
\hline غلظت . عصاره & - & - & - & $+1+\Delta$ & $.1+.1$ & 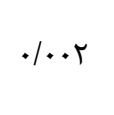 & $*+\cdot r$ & r. & . & r. \\
\hline غلظت . . عصاره & - & - & - & $.1 \cdot 1$ &.$/+r$ & . & $.1+.1$ & $\cdot 1 \cdot+1$ & $\cdot 1+\cdot 1$ & $.1+\cdot 1$ \\
\hline دَزامتازون & - & - & - & $\cdot|\cdot r|$ & $\cdot / \cdot v$ & $\cdot 1 \cdot+)^{c}$ & $.1+.1$ & $\cdot 1+.1$ & $\cdot 1 \cdot \cdots 1$ & $\cdot \mid \cdots+$ \\
\hline گروه ميكس & - &.$/ \cdot \mathrm{IV}$ & $\cdot / \cdot V$ & . &.$|\cdots|$ &.$|\cdots|$ & $+|\cdots|$ & $\cdot|\cdots|$ & $\cdot|\cdots|$ & $+|\cdots|$ \\
\hline
\end{tabular}




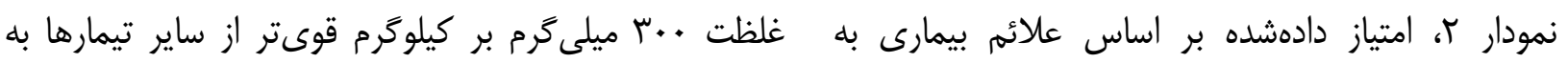

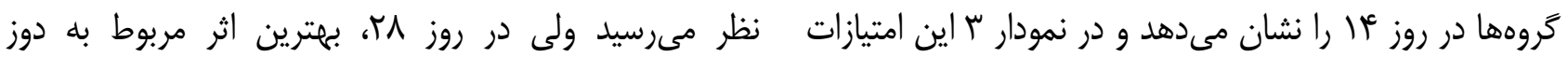

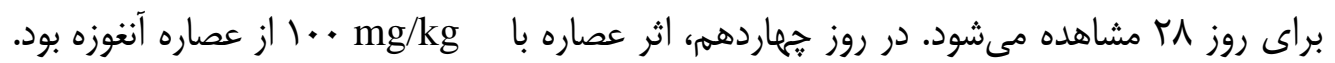

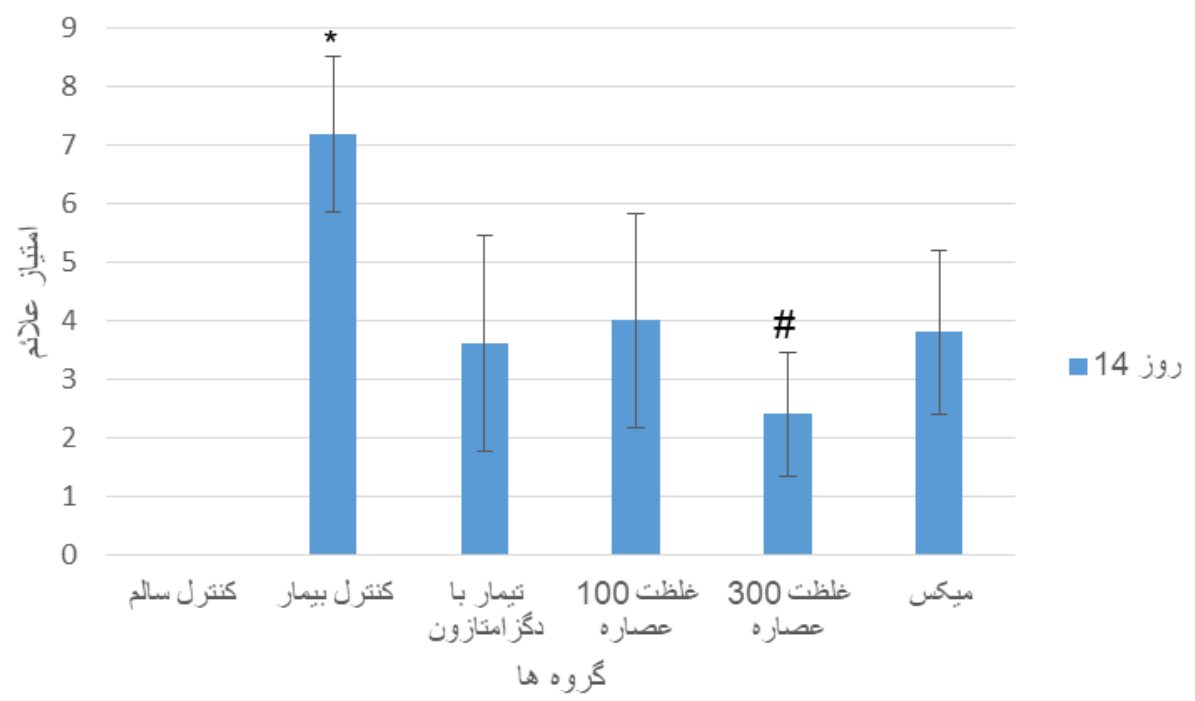

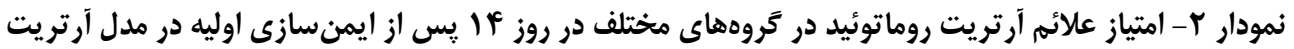

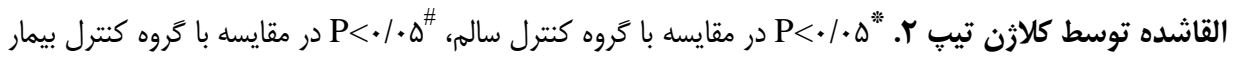

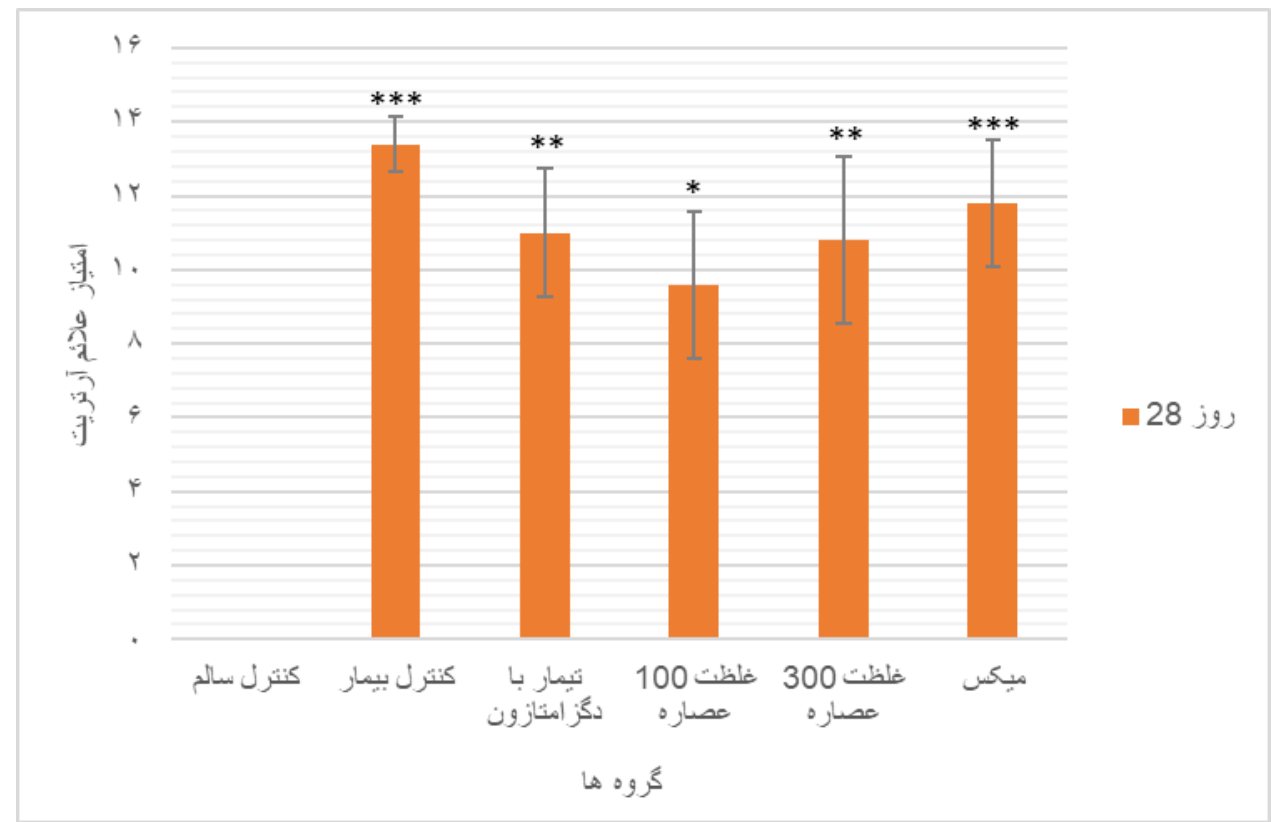

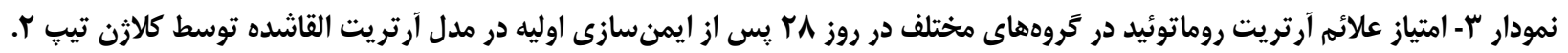

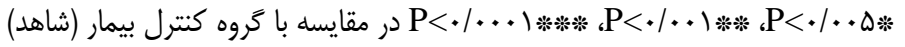


جدول ب- تغييرات وزن تَروهاى مختلف مورد مطالعه در طى f هفته آزمايش (به كَرم)

\begin{tabular}{|c|c|c|c|c|c|c|c|c|c|c|}
\hline \multicolumn{2}{|c|}{ تغييرات كلى وزن } & \multicolumn{2}{|c|}{ تغييرات وزن هفته } & \multicolumn{2}{|c|}{ تغييرات وزن هفته } & \multicolumn{2}{|c|}{ تغييرات وزن هفته } & \multicolumn{2}{|c|}{ تغييرات وزن هفته } & \multirow{2}{*}{ تحروه } \\
\hline انحراف & ميانكين & انحراف & ميانكين & انحراف & ميانكين & انحراف & ميانغين & انحراف & ميانكَين & \\
\hline$V / T F$ & Q) & $r / T \Lambda$ & $11 / 9$ & $r / 19$ & $9 / 1$ & $r / \mathcal{N}$ & $1 . / \pi$ & s/sD & $19 / r^{c}$ & كنترل سالم \\
\hline$q / v r$ & $r \Delta / \Lambda$ & $r / q \varepsilon$ & $s / \pi$ & $r / \Delta \Lambda$ & $V / \Lambda$ & 1.109 & $-8 / 8$ & $8 / 1$. & $r N / F$ & كنترل بيمار \\
\hline $0 / 4 q$ & ه/ & 81.9 & r & $\Gamma / \Lambda$. & 9 & $s / V^{N}$ & $\Delta / \&$ & $\Delta / \sim_{\Delta}$ & $r \pi / r$. & تيمار با دكزامتازون \\
\hline $11 / r \Delta$ & rN/A & $9 / .9$ & $8 / 8$ & Q/r & $\cdot / 1$ & $\Delta / \cdot 1$ & $\mathrm{r} / \Lambda$ & $1 . / \Delta C$ & $T V / S$ & غلظت ع عاره \\
\hline $9 / \Delta \Delta$ & « & $\Gamma / \Delta \Lambda$ & $r / \mathcal{E}$ & r/ז & $-r / s$ & $s / 4$. & 1. & $r / \pi$. & rq & غلظت ع +." \\
\hline $9 / r q$ & rq/8 & $1.1 . r$ & $9 / \Delta$ & r/f & $-\Delta / r$ & $8 / 09$ & v & $r / \mu$ & $r \Delta / r$ & كروه ميكس \\
\hline \multicolumn{2}{|c|}{.11 .9} & \multicolumn{2}{|c|}{.109} & \multicolumn{2}{|c|}{.$|\cdots|$} & \multicolumn{2}{|c|}{$\% v$} & \multicolumn{2}{|c|}{. } & P-value \\
\hline
\end{tabular}

vivo تغييرات وزن: براى بررسى اثر عصاره بر بيمارى، از امتيازدهى بر اساس

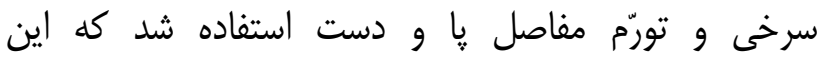
جدول r نشاندهنده ميزان تغيير وزن وزئن حيوانات مورد امتيازدهى شاخصى از شدت التهاب و يا شدت بـ بيمارى است

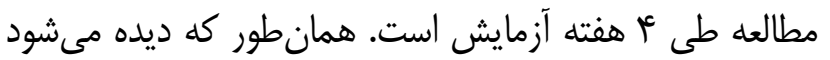

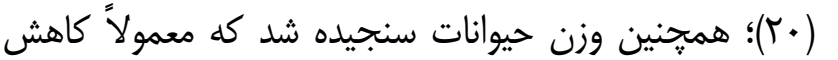

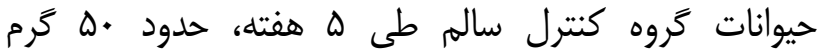
وزن يا عدم افزايش وزن كافى در مدل حيوانى اين بيمارى از

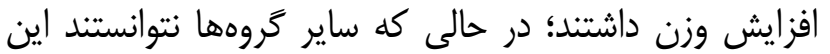

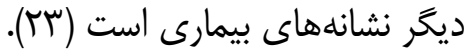

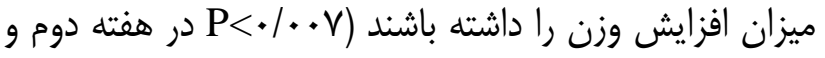

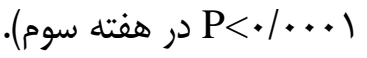

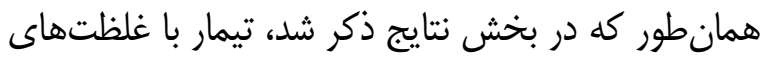
تخفف عائ تخفيف علائم بيمارى و جلوگيرى از بروز شديد علائم در در اين مطالعه، بيمارى آرتريت روماتوئيد با تزريق كلاثن

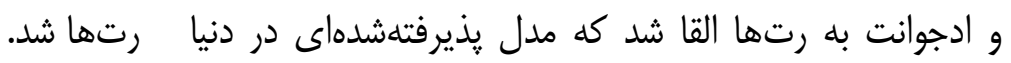
مطالعه ما نشان مئدهد كه عصاره صمغ آنغوزه

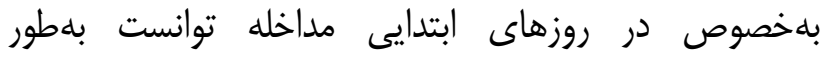
بلهُخوص براى مطالعه داروهاى جديد است. اين مدل از نظر

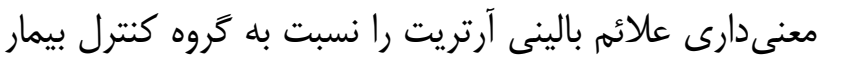

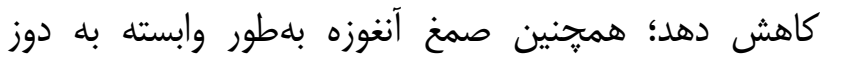

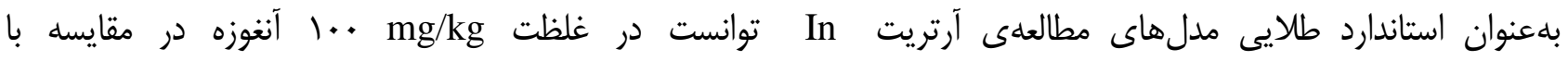




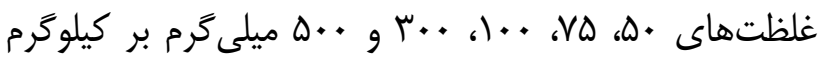

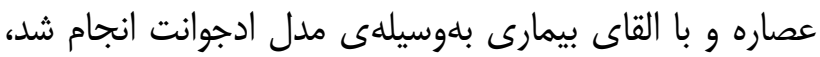

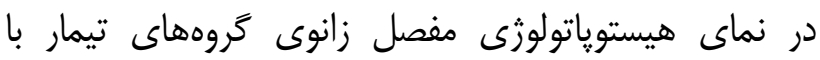

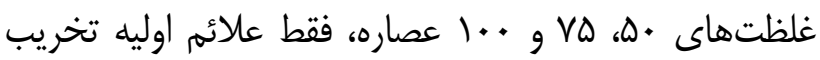
غضروف و استخوان نمايان شد كه نقش ييشخيرى كنندهى اين گياه را در روند تخريبى آرتريت روماتوئيد به اثبات

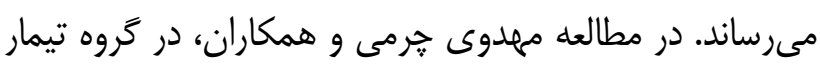

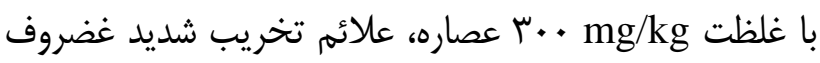

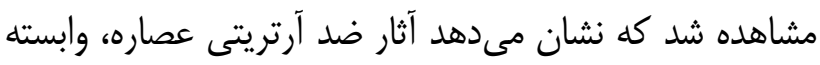

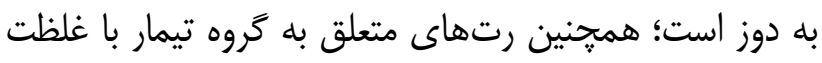

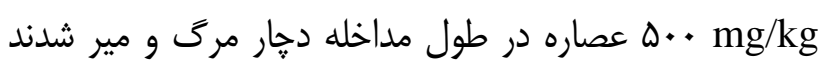

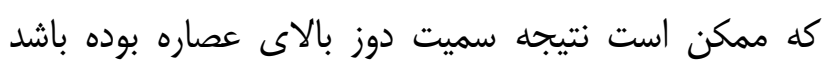

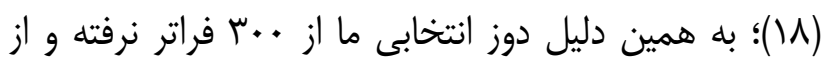

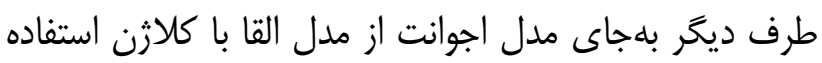
شد كه امتيازات زير را دارد:

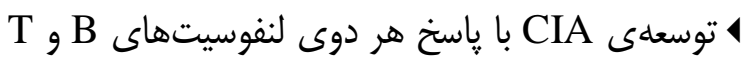

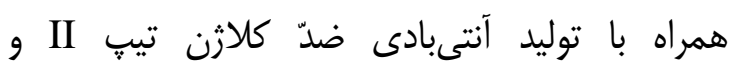
سلولهاى T اختصاصى كلاثن همراه است.

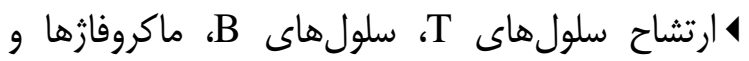

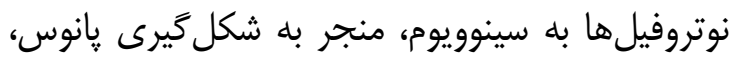

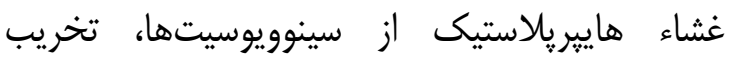

$$
\text { غضروف و استخوان، مىشود. }
$$

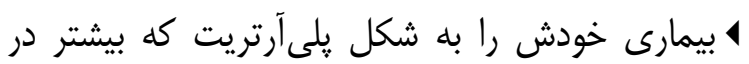

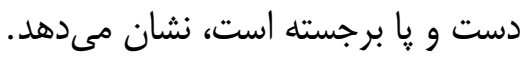
همانطور كه اشاره شد اين بيمارى بر الكوى تغييرات

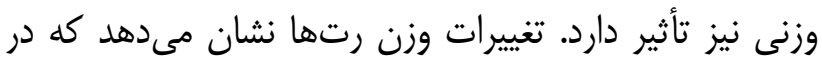

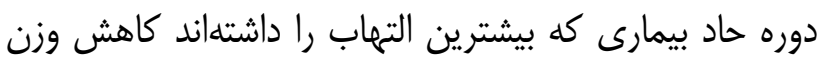
محسوس بوده است كه اين كاهش در گروه كنترل بيمار

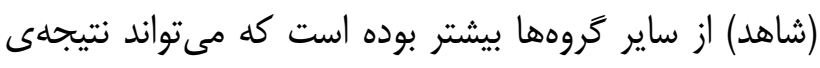
اثر واسطه هاى التهابى مانند

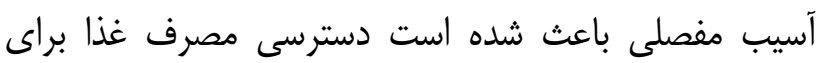
حيوانات بيمار دشوار باشد.
دَزامتازون كه داروى رايج ضدّ التهاب است و عوارض جانبى متعددى دارد، عملكرد بهترى در بهبود علائم آرتريت ايفا كند.

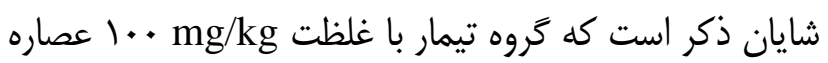

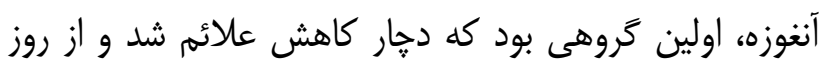

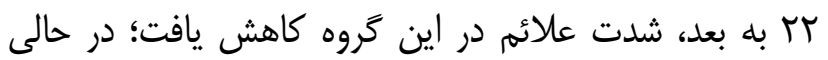

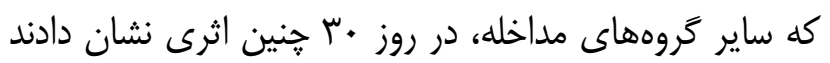

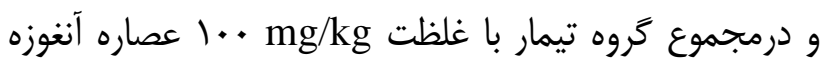

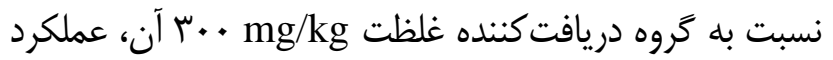
بهترى در بهبود علائم بالينى داشت.

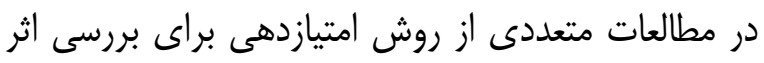

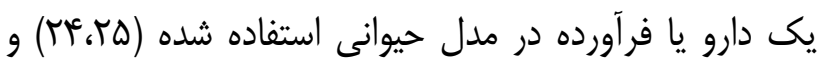

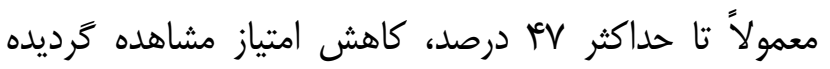

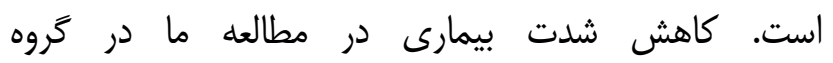

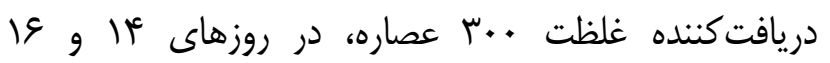

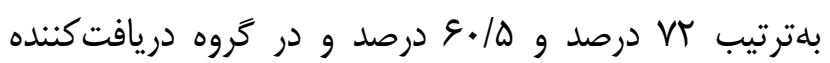

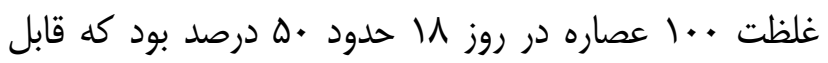
توجه مىباشد. نتايج مطالعه حاضر با ساير مطالعاتى كه از همين روش

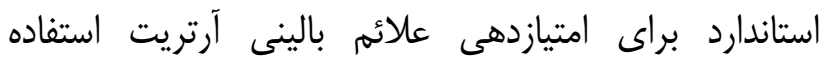

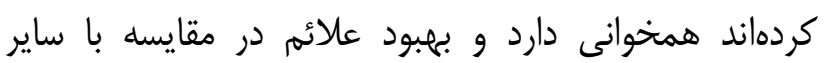

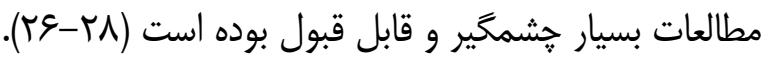

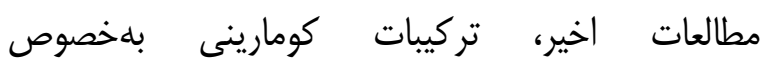
سزكوئىترين كومارينها (آمبلىيرنين) كه از تركيبات اصلى إنى

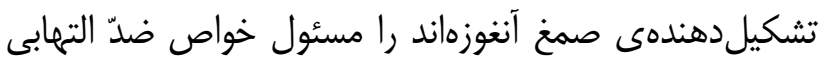

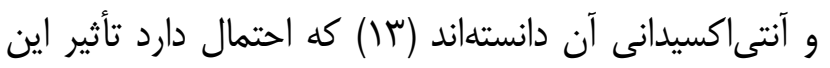

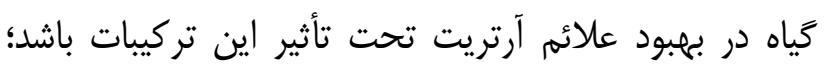
البته شناخت دقيق تركيبات دخيل نياز به مطالعات بيشتر دارد.

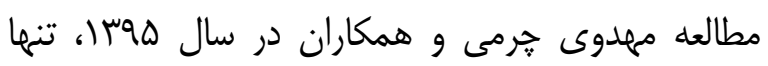
مطالعهاى است كه در آن اثر صمغ آنغوزه بر آرتريت روماتوئيد

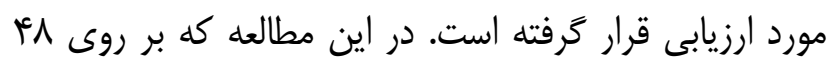

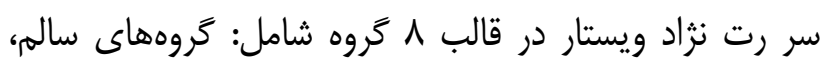

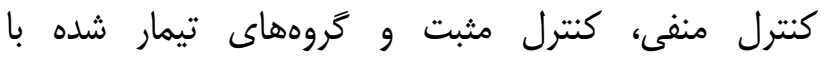




\section{تقدير و تشكر}

اين مقاله حاصل همكارى دانشخاه شاهد و دانشخاه علوم

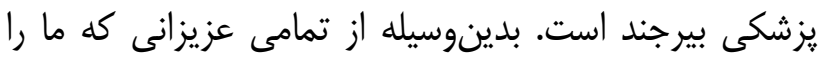

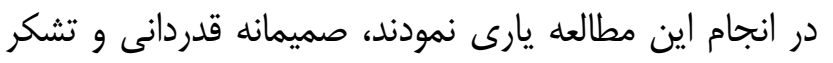

مىنماييهم.

تضاد منافع:

اعلام مى كنند كه هيجگَّنه تضاد منافعى

نويسندكان

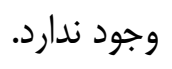

نتيجه Fيرى

اين مطالعه نشان مى دهدي كه عصاره صمغ آنغوزه مىتواند

سبب كاهش شدت علائم ظاهرى بيمارى آرتريت روماتوئيد

شود، اما براى روشن كردن اينكه كاهش عالائم بيمارى بلهدليل

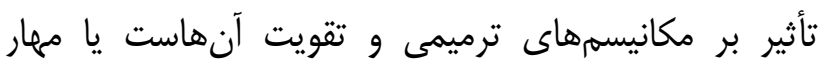

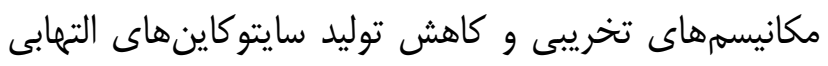

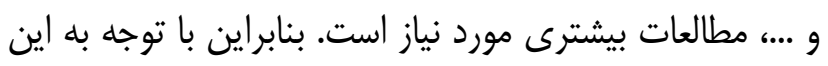

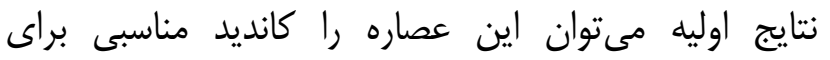

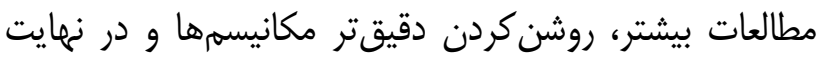

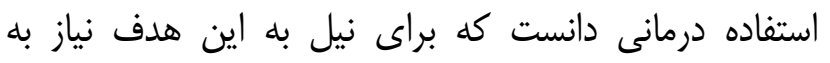

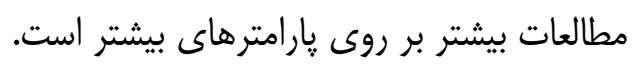

منابع:

1- Farzaei MH, Farzaei F, Abdollahi M, Abbasabadi Z, Abdolghaffari AH, Mehraban B. A mechanistic review on medicinal plants used for rheumatoid arthritis in traditional Persian medicine. J Pharm Pharmacol. 2016; 68(10): 123348. doi: 10.1111/jphp.12606.

2- Gibofsky A. Overview of epidemiology, pathophysiology, and diagnosis of rheumatoid arthritis. Am J Manag Care. 2012; 18(13 Suppl): S295-302.

3- Tsuji G, Koshiba M, Nakamura H, Kosaka H, Hatachi S, Kurimoto C, et al. Thioredoxin protects against joint destruction in a murine arthritis model. Free Radic Biol Med. 2006; 40(10): 1721-31. DOI: 10.1016/j.freeradbiomed.2006.01.006

4- McInnes IB, Schett G. Cytokines in the pathogenesis of rheumatoid arthritis. Nat Rev Immunol. 2007; 7(6): 429-42. DOI: $10.1038 /$ nri2094

5- Vierboom MP, Jonker M, Tak PP, Bert A. Preclinical models of arthritic disease in non-human primates. Drug Discov Today. 2007; 12(7-8): 327-35. DOI: 10.1016/j.drudis.2007.02.012

6- Umar S, Kumar A, Sajad M, Zargan J, Ansari MM, Ahmad S, et al. Hesperidin inhibits collagen-induced arthritis possibly through suppression of free radical load and reduction in neutrophil activation and infiltration. Rheumatol Int. 2013; 33(3): 657-63. doi: 10.1007/s00296-012-2430-4.

7- Seidemann J. World spice plants. Verlang Berlin Heldelberg. New York: Springer; 2005.

8- Zarekarizi AR, Omidi M, Fallah Hoseini H, Yazdani D, Rezazadeh S, Irvani N, et al. A Review on pharmacological effects of Ferula assa-foetida L.: A systematic review. J Med Plants. 2011; 4(40): 17-25. [Persian]

9- Leaman DJ. Medicinal plant conservation, Newsletter of the medicinal plant specialist group of the IUCN species survival commission. Silphion. 2006; 13: 24-6.

10- Ross IA. Medicinal Plants of the World. Totowa, New Jersey: Humana Press; 2010.

11- Khosravi H, Mehrabi A. Economic study of Ferula harvesting in Tabass region. Iranian Journal of Natural Resources. 2006; 58(4): 933-944. [Persian]

12-Zare AR, Omidi M, Fallah Hoseini H, Yazdani D, Rezazadeh S, Irvani N, Oladzad A. A review on pharmacological effects of Ferula assa-foetida L.: A systematic review. Journal of Medicinal Plants. 2011 Dec 15;4(40):17-25.

13- Iranshahy M, Iranshahi M. Traditional uses, phytochemistry and pharmacology of asafoetida (Ferula assa-foetida oleo-gum-resin)_A review. J Ethnopharmacol. 2011; 134(1): 1-10. doi: 10.1016/j.jep.2010.11.067 
14- Amalraj A, Gopi S. Biological activities and medicinal properties of Asafoetida: A review. J Tradit Complement Med. 2017; 7(3): 347-59.

15- Abolhassanzadeh Z, Aflaki E, Yousefi G, Mohagheghzadeh A. Medicinal Plants for Joint Pain in Traditional Persian Medicine. Trends in Pharmaceutical Sciences. 2016; 2(2): 89-100.

16- Geroushi A, Auzi AA, Elhwuegi AS, Elzawam F, El-Sherif A, Nahar L, et al. Antinociceptive and antiinflammatory activity of Ferula hermonis root oil in experimental animals. Lat Am J Pharm. 2010; 29(8): 1436-9.

17- Amiri A, Jomehpour N. Evaluation the Effect of Anti bacterial of Ferula assa-foetida L, Carum copticum, Mentha piperita L Hydroalcoholic Extract on Standard Sensitive and Methicillin-Resistant Staphylococcus aureus, Escherichia coli O157H7 and Salmonella typhimurium. J Ilam Univ Med Sci. 2016; 24(2): 72-9. [Persian]

18- Mahdavi Charami M, Tehranipour M, Mahdavi Shahri N. Effect of asafoetida resin hydroalcoholic extract on experimental rheumatoid arthritis in rat. Pejouhesh dar Pezeshki. 2017; 40(4): 172-7. [Persian]

19- Brand DD, Latham KA, Rosloniec EF. Collagen-induced arthritis. Nat Protoc. 2007; 2(5): 1269-75. DOI: 10.1038/nprot.2007.173

20- Rosloniec EF, Cremer M, Kang AH, Myers LK, Brand DD. Collagen-induced arthritis. Curr Protoc Immunol. 2010 Apr;89(1): 15.5.1-15.5.25. doi: 10.1002/0471142735.im1505s89

21- Bessis N, Decker P, Assier E, Semerano L, Boissier MC. Arthritis models: usefulness and interpretation. InSeminars in immunopathology 2017 Jun 1 (Vol. 39, No. 4, pp. 469-486). Springer Berlin Heidelberg.

22- Asquith DL, Miller AM, McInnes IB, Liew FY. Animal models of rheumatoid arthritis. Eur J Immunol. 2009; 39(8): 2040-4. doi: 10.1002/eji.200939578.

23- Kocyigit A, Guler EM, Kaleli S. Anti-inflammatory and antioxidative properties of honey bee venom on Freund's Complete Adjuvant-induced arthritis model in rats. Toxicon. 2019; 161: 4-11. doi: 10.1016/j.toxicon.2019.02.016.

24- Jing R, Ban Y, Xu W, Nian H, Guo Y, Geng Y, et al. Therapeutic effects of the total lignans from Vitex negundo seeds on collagen-induced arthritis in rats. Phytomedicine. 2019; 58: 152825. doi: 10.1016/j.phymed.2019.152825.

25- Kumar R, Singh S, Saksena AK, Pal R, Jaiswal R, Kumar R. Effect of Boswellia serrata extract on acute inflammatory parameters and tumor necrosis factor- $\alpha$ in complete Freund's adjuvant-induced animal model of rheumatoid arthritis. Int J Appl Basic Med Res. 2019; 9(2): 100-6. doi: 10.4103/ijabmr.IJABMR_248_18.

26- Tu YW, Wang K, Liang Y, Jia X, Wang L, Wan JB, et al. Glycine tabacina ethanol extract ameliorates collageninduced arthritis in rats via inhibiting pro-inflammatory cytokines and oxidation. J Ethnopharmacol. 2019; 237(12): 207.

27- Guo Y, Ye Q, Yang S, Wu J, Ye B, Wu Y, et al. Therapeutic effects of polysaccharides from Anoectochilus roxburghii on type II collagen-induced arthritis in rats. Int J Biol Macromol. 2019; 122: 882-92. doi: 10.1016/j.ijbiomac.2018.11.015.

28- Aswathy IS, Krishnan S, Peter J, Sabu V, Helen A. Scientific validation of Anti-arthritic effect of Kashayams-a polyherbal formulation in collagen induced arthritic rats. J Ayurveda Integr Med. 2019. pii: S0975-9476(17)30742-8. doi: 10.1016/j.jaim.2018.02.139. 